\title{
Evaluation of the Efficiency of Ethanol Precipitation and Ultrafiltration on the Purification and Characteristics of Exopolysaccharides Produced by Three Lactic Acid Bacteria
}

\author{
Manel Ziadi $\mathbb{D}^{1}{ }^{1}$ Taroub Bouzaiene, ${ }^{1}$ Sana M'Hir, $^{1}{ }^{1}$ Kaouther Zaafouri, ${ }^{1}$ \\ Ferid Mokhtar, ${ }^{2}$ Mokhtar Hamdi, ${ }^{1}$ and Claire Boisset-Helbert ${ }^{3}$ \\ ${ }^{1}$ Laboratory of Microbial Ecology and Technology, LETMi-INSAT, National Institute of Applied Sciences and Technology INSAT, \\ Carthage University, 2 Boulevard de la Terre, BP 676, 1080 Tunis, Tunisia \\ ${ }^{2}$ Centre de Recherche sur les Macromolécules Végétales, CERMAV, CNRS, 601 rue de la Chimie, 38041 Grenoble Cedex 9, France \\ ${ }^{3}$ National Research Center for Materials Science, Borj-Cedria Technopark, BP N 73, 8027 Soliman, Tunisia
}

Correspondence should be addressed to Manel Ziadi; manel_z52@yahoo.fr

Received 29 April 2018; Accepted 9 August 2018; Published 18 September 2018

Academic Editor: Taoufik Ghrairi

Copyright (c) 2018 Manel Ziadi et al. This is an open access article distributed under the Creative Commons Attribution License, which permits unrestricted use, distribution, and reproduction in any medium, provided the original work is properly cited.

\begin{abstract}
Exopolysaccharides (EPS) produced by three Lactic Acid Bacteria strains, Lactococcus lactis SLT10, Lactobacillus plantarum C7, and Leuconostoc mesenteroides B3, were isolated using two methods: ethanol precipitation (EPS-ETOH) and ultrafiltration (EPS$\mathrm{UF}$ ) through a $10 \mathrm{KDa}$ cut-off membrane. EPS recovery by ultrafiltration was higher than ethanol precipitation for Lactococcus lactis SLT10 and Lactobacillus plantarum C7. However, it was similar with both methods for Leuconostoc mesenteroides B3. The monomer composition of the EPS fractions revealed differences in structures and molar ratios between the two studied methods. EPS isolated from Lactococcus lactis SLT10 are composed of glucose and mannose for EPS-ETOH against glucose, mannose, and rhamnose for EPS-UF. EPS extracted from Lactobacillus plantarum C7 and Leuconostoc mesenteroides B3 showed similar composition (glucose and mannose) but different molar ratios. The molecular weights of the different EPS fractions ranged from 11.6 \pm 1.83 to $62.4 \pm 2.94 \mathrm{kDa}$. Molecular weights of EPS-ETOH fractions were higher than those of EPS-UF fractions. Fourier transform infrared (FTIR) analysis revealed a similarity in the distribution of the functional groups $(\mathrm{O}-\mathrm{H}, \mathrm{C}-\mathrm{H}, \mathrm{C}=\mathrm{O},-\mathrm{COO}$, and $\mathrm{C}-\mathrm{O}-\mathrm{C}$ ) between the EPS isolated from the three strains.
\end{abstract}

\section{Introduction}

Exopolysaccharides (EPS) are long-chain polymers, industrially used as thickeners, stabilizers, and gelling agents in food products. More recently they were used as depollution agents and there was a growing interest in their biological functions like antitumor, antioxidant, or prebiotic activities [1]. Exopolysaccharides are produced by the metabolic processes of microorganisms such as bacteria, fungi, and blue-green algae [2]. Bacterial Exopolysaccharides are widely described in the literature, offering a wide range of biological and physicochemical properties.

Lactic Acid Bacteria (LAB) represent a natural source of EPS which play an important role in the rheological behavior and texture of fermented milks [3-5]. Most LAB producing
EPS belong to the genera Streptococcus, Lactobacillus, Lactococcus, Leuconostoc, and Pediococcus [6].

EPSs from LAB can be classified into two groups: homopolysaccharides and heteropolysaccharides. Homopolysaccharides consist of repeating units of only one type of monosaccharide (D-glucose or D-fructose) and can be divided into two major groups: glucans and fructans. By contrast, heteropolysaccharides, produced by a great variety of mesophilic and thermophilic LAB, are formed by repeating units that most often contain a combination of D-glucose, D-galactose, and L-rhamnose and, in a few cases, $\mathrm{N}$-acetylglucosamine (GlcNAc), $\mathrm{N}$-acetylgalactosamine (GalNAc), or glucuronic acid (GlcA). Sometimes, noncarbohydrate substituent such as phosphate, acetyl, and glycerol are present. The molecular mass of these polymers ranges 
between 40 and $6000 \mathrm{kDa}$ [4]. Heteropolysaccharides from LAB demonstrate different structures [7]. The heteropolysaccharides are constructed from multiple copies of oligosaccharides, which contain between three and eight residues. Two or more different monosaccharides are usually present in each repeating unit and show different linkage patterns [8].

EPSs produced by LAB are in great variety, depending on LAB strains, culture conditions, and medium composition [9], and often differ by monosaccharides composition, charge, linkages between units, and presence of repeated side chains. The sugar components of EPS from LAB are most commonly galactose, glucose, and rhamnose [3]. The EPSs isolated from some strains of $L c$. lactis subsp. cremoris contain rhamnose, glucose, galactose, and phosphates [10-12], while others contain only glucose and galactose. Marshall et al. [13] found that Lc. lactis subsp. cremoris LC330 produced two EPSs with different sugar composition and molecular mass: a neutral EPS of $1.106 \mathrm{kDa}$ and a smaller negatively charged EPS (containing phosphate groups) of about $1.104 \mathrm{kDa}$. Van Casteren et al. [14] reported that EPS from Lc. lactis subsp. cremoris $\mathrm{B} 40$ consists of rhamnose, galactose, and glucose in the ratio of 0.9:1.2:2.0 and that the molar ratio of carbohydrate and phosphorus is 4.7:1. Streptococcus thermophilus produce an EPS composed of galactose and rhamnose when grown on milk [9]. Lactobacillus bulgaricus grown on chemically defined medium produce an EPS composed of galactose, glucose, and rhamnose [15]. Many strains of Leuconostoc mesenteroides produce dextran ( $\alpha$-glucan). Levans are produced by several strains of Streptococcus mutans [3].

Wide range of exopolysaccharides extraction, purification, and analysis schemes have been developed in literature involving from simple dialysis against water of the culture medium following by freeze drying to size exclusion column for preparing of highly pure EPS extracts.

Some authors used trichloroacetic acid (TCA) for protein sedimentation, dialysis for final EPS purification from sugars, or just numerous precipitations with ethanol and/or acetone [6]. Others procedures have been used for EPS purification including microfiltration, ultrafiltration, and diafiltration which can be carried out separately or in combination with ethanol precipitation [16-18]. Different types of membranes have been used such as regenerated cellulose and polyethersulfone, as well as different molecular weight cut-off [19].

In order to obtain pure polysaccharide fractions, size exclusion chromatography is the most common method used because it allows the separation of polysaccharides according to their size and also permits the subsequent determination of their molecular weight [19].

These different methods can be compared according to two criteria: quantity and quality of extracted EPS. It was shown that different extraction procedures influence the quantity and the composition of the extracted EPS [20, 21], the quantity and the composition of the mineral fraction present in the EPS extracts [22], and EPS binding properties to protons and different metals [20, 23, 24].

More advanced technologies to obtain polysaccharides have been used recently, as ultrasonic [25] and microwave assisted extractions [26] besides the pressurized solvent extraction [27]. The latter procedure showed to be faster and more efficient in obtaining higher yield of polysaccharides, comparing to the traditional methodologies.

In the present study, we characterized the EPS fractions obtained from pure bacterial culture of Lactococcus lactis subsp. lactis var. diacetylactis SLT10 (Lc. lactis SLT10), Lactobacillus plantarum C7 ( Lb. plantarum C7), and Leuconostoc mesenteroides B3 (Ln. mesenteroides B3) to evaluate the influence of purification methods on the EPS yield, composition, and molecular weight. The studied purification methods were ethanol precipitation and ultrafiltration.

\section{Material and Methods}

2.1. Bacterial Strains. The three studied strains were obtained from the strain collection of Laboratory of Microbial Ecology and Technology (LETMi): Lactococcus lactis subsp. lactis SLT10 strain had been previously isolated in our laboratory from Tunisian traditional fermented milk [28]. Lactobacillus plantarum C7 ( $L b$. plantarum C7) had been isolated from gastrointestinal tract of chickens [29] and Leuconostoc mesenteroides B3 (Ln. mesenteroides B3) had been isolated from Tunisian palm sap [30]. Stock cultures grown in MRS broth were stored at $-18^{\circ} \mathrm{C}$ in $50 \%$ glycerol until use.

2.2. Fermentation. The MRS-sucrose medium was used for EPS production and contain: $4 \%(\mathrm{w} / \mathrm{v})$ sucrose, $10 \mathrm{~g} / \mathrm{L}$ tryptone, $10 \mathrm{~g} / \mathrm{L}$ meat extract, $5 \mathrm{~g} / \mathrm{L}$ yeast extract, $5 \mathrm{~g} / \mathrm{L}$ sodium acetate, $2 \mathrm{~g} / \mathrm{L}$ disodium phosphate, $2 \mathrm{~g} / \mathrm{L}$ tri-ammonium

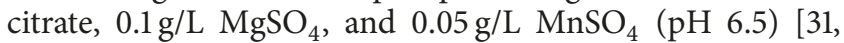
32]. The medium was autoclaved at $121^{\circ} \mathrm{C}$ for $15 \mathrm{~min}$. The fermentation temperature, inoculum size, and fermentation time were $30^{\circ} \mathrm{C}, 3.0 \%(\mathrm{v} / \mathrm{v})$, and $24 \mathrm{~h}$, respectively. After incubation, bacterial cells were separated from the EPS preparation by centrifugation $\left(5,000 \mathrm{rpm}\right.$ for $10 \mathrm{~min}$ at $\left.4^{\circ} \mathrm{C}\right)$ of the culture broth. The supernatant, containing the EPS fraction, was filtered under vacuum through Sartorius cellulose nitrate filters of $(0.45 \mu \mathrm{m}$ pore size $)$ to eliminate cells and large cellular. The obtained supernatant was divided into two batches for the purification step.

2.3. Purification of Exopolysaccharides. The obtained supernatant was divided in two batches. The first supernatant was treated with $\mathrm{NaCl}$ to a final concentration of $1 \mathrm{M}$. EPS was precipitated by the addition of v/v chilled ethanol (96\%) to the supernatant (EPS-ETOH). The proportion of chilled ethanol (v/v) was chosen in order to precipitate highmolecular weight exopolysaccharides. After precipitation at $4^{\circ} \mathrm{C}$ (overnight) the sample was centrifuged at $6,000 \mathrm{rpm}$ for $20 \mathrm{~min}$ at $4^{\circ} \mathrm{C}$, and the pellet was washed with ethanol (96\%) and recentrifuged at $6,000 \mathrm{rpm}$ for $20 \mathrm{~min}$ at $4^{\circ} \mathrm{C}$. The pellet obtained was redissolved in distilled water and lyophilized.

The second supernatant was ultrafiltrated (UF) using a $10 \mathrm{kDa}$ cut-off cellulose membrane. Finally, the exopolysaccharide fraction (EPS-UF), collected from the retentate, was evaporated and lyophilized.

\subsection{Exopolysaccharides Characterization}

2.4.1. Monosaccharide Analysis. The monomer composition of exopolysaccharides extracted from the three studied 
strains was determined after preparation of methyl glycosides trimethylsylil derivatives. Suspensions were prepared by dissolving $4 \mathrm{mg}$ of lyophilized polysaccharides in $2 \mathrm{~mL}$ distilled water. Fifty $\mu \mathrm{L}$ of myo-inositol, used as internal standard, was added to $200 \mu \mathrm{L}$ of polysaccharides suspension. The mixture was hydrolyzed for $4 \mathrm{~h}$ at $100^{\circ} \mathrm{C}$, in screw glass tube, using $500 \mu \mathrm{L}$ of methanol/HCl (3 N) (Supelco). After cooling to room temperature, methanolyzate fractions were neutralized with silver carbonate, centrifuged at $6,000 \mathrm{rpm}$ for $5 \mathrm{~min}$, and evaporated under nitrogen flow. The generated methyl glycosides were then converted to their corresponding volatile trimethylsilyl derivatives. The reaction took place by adding $70 \mu \mathrm{L}$ pyridine and $70 \mu \mathrm{L}$ derivatization reagent, Bis(tri-methylsilyl) trifluoroacetamide (BSTFA) + $1 \%$ trimethylchlorosilane (TMCS) (Supelco), incubated for $30 \mathrm{~min}$ at $80^{\circ} \mathrm{C}$. After solvent evaporation under nitrogen flow, the generated per-O-trimethylsilylmethyl glycosides were resuspended in $700 \mu \mathrm{L}$ dichloromethane and analyzed by gas chromatography-flame ionization detector (GC-FID). An Agilent GC 6850A instrument equipped with HP5MS capillary column ( $30 \mathrm{~m}$ length, $0.25 \mathrm{~mm}$ diameter, and $0.25 \mu \mathrm{m}$ film thicknesses) was used. The GC oven temperature was set to $120^{\circ} \mathrm{C}$, increased first to $180^{\circ} \mathrm{C}$ at $3^{\circ} \mathrm{C} / \mathrm{min}$, then increased to $200^{\circ} \mathrm{C}$ at $2^{\circ} \mathrm{C} / \mathrm{min}$, and held for $5 \mathrm{~min}$. The helium carrier gas flow was set at $1.5 \mathrm{~mL} / \mathrm{min}$ and the injection volume was $0.1 \mu \mathrm{L}$.

2.4.2. Molecular Mass Determination. The average molecular mass of exopolysaccharides extracted from the three studied strains was determined using high-performance size exclusion chromatography (HPSEC) equipped with Shodex OHpak SB-804 HQ and SB-805 HQ columns placed in series. The EPS was eluted with $0.1 \mathrm{M}$ Sodium Nitrate $\left(\mathrm{NaNO}_{3}\right)$ at a flow rate of $0.5 \mathrm{~mL} \cdot \mathrm{min}^{-1}$. Detection was performed using a refractive index detector (RI) (Waters) and a multiangle laserlight scattering detector (LS) (MiniDAWN, Wyatt Technology, Dawn).

2.4.3. Fourier Transform Infrared (FTIR) Spectroscopy of Purified EPS. The structural characterization of the purified EPS was studied using Fourier transform infrared (FTIR) spectroscopy in order to determine their functional groups distribution. The translucent pellets $(5 \mathrm{~mm} \varnothing)$ were made by mixing and pressing the freeze-dried polysaccharides samples with $\mathrm{KBr}$ powder $(5: 100 \mathrm{w} / \mathrm{w})$. The FTIR spectra were recorded in transmittance mode at a spectral range of 4000 and $400 \mathrm{~cm}^{-1}$ with an accumulation of 15 scans and a resolution was $4 \mathrm{~cm}^{-1}$, using a spectrophotometer type Perkin Elmer Spectrum BX ${ }^{\circledR}$, equipped with a He-Ne laser and a detector MCT type broadband and high sensitivity [33]. The spectra acquisition was performed via spectrum v5.3.1 software. The bands identification was accomplished according to the data cited by Wiercigroch et al. [34].

\subsection{Analytical Methods}

2.5.1. Total Sugar Determination. Total carbohydrate content of the exopolysaccharides obtained by ethanol precipitation and ultrafiltration was estimated by the phenol-sulfuric acid calorimetric method [35]. A $200 \mu$ l EPS sample solution $\left(10 \mathrm{mg} . \mathrm{mL}^{-1}\right)$ was treated with $200 \mu \mathrm{l}$ of a $5 \%$ phenol solution and $1 \mathrm{ml}$ of pure $\mathrm{H}_{2} \mathrm{SO}_{4}$. The mixture was cooled to room temperature for $30 \mathrm{~min}$. Absorbance at $492 \mathrm{~nm}$ of samples as well as standard sugar (10 to $100 \mu \mathrm{g} \cdot \mathrm{mL}^{-1}$ ribose) was read by spectrophotometry (Hitachi U-1800 ${ }^{\circledR}$ ).

2.5.2. Protein Concentration Measurement. Protein content was calculated according to the Bradford's method [36]. $1 \mathrm{~mL}$ of reagent (Biorad) was added to $20 \mu \mathrm{L}$ of sample $\left(10 \mathrm{mg} \cdot \mathrm{mL}^{-1}\right)$ and incubated $5 \mathrm{~min}$ at room temperature. OD of samples as well as the standard protein ( 0 to $0.75 \mathrm{mg} \cdot \mathrm{mL}^{-} 1$ of Bovine Serum Albumin (BSA)) was measured at $595 \mathrm{~nm}$ (Hitachi U-1800 ${ }^{\circledR}$ ).

2.6. Statistical Analysis. All experiments were performed in triplicate and are reported as means \pm standard deviation. Significant differences between samples were tested using a two-sample comparison analysis and a $t$-test. The statistical significance of the relationship was analyzed at the $95 \%$ confidence level.

\section{Results and Discussion}

The three studied strains were isolated from different ecological niches. Lc. lactis SLT10 is a starter used for the preparation of "Leben" a Tunisian fermented milk; Lb. plantarum C7 is a probiotic strain isolated from gastrointestinal tract of chickens. For both strains, characterization of EPS produced can provide important data concerning their uses as starters for the preparation of fermented functional foods. As regards Ln. mesenteroides B3, this is the first time that a strain isolated from Tunisian palm sap was investigated for EPS production.

3.1. Effect of Purification Method on Exopolysaccharides Yield. In order to isolate EPS produced by the three studied strains, two purification methods were used: ethanol precipitation and ultrafiltration (UF) through $10 \mathrm{kDa}$ membrane. Molar exclusion limit of $10 \mathrm{kDa}$ has been chosen based on preliminary study showing that bacterial polysaccharides fractions presented molecular weight higher than $10 \mathrm{kDa}$. Moreover, with molecular weight cut-off of $10 \mathrm{kDa}$ high- and low-molecular weight, polysaccharides are retained, while oligosaccharides, polypeptides, and so forth are removed.

The evaluation of the efficiency of both methods on polysaccharides recovery after purification step was conducted using the phenol-sulfuric method described by Dubois et al. [35] for the determination of sugars and related compounds on the freeze-dried extract. This method has been widely used as an indication of the EPS yield after different purification methods. Results are summarized in Table 1.

As shown in Table 1, EPS recovery by UF was significantly higher than ethanol precipitation for Lc. lactis SLT10 and Lb. plantarum C7 $(\mathrm{t}<0.05)$. UF was more efficient than ethanol precipitation method (1.2 times more). However, EPS recovery was similar for both methods for $\mathrm{Ln}$. mesenteroides B3. Indeed, UF is widely used method for polysaccharides 
TABLE 1: Reducing sugars contents (\%) of different exopolysaccharides fractions.

\begin{tabular}{lcc}
\hline Strains & EPS-ETOH & EPS-UF \\
\hline Lc. Lactis SLT10 & $28.06 \pm 0.041$ & $33.63 \pm 1.38$ \\
Lb. plantarum C7 & $19.82 \pm 0.305$ & $26.54 \pm 0.905$ \\
Ln. mesenteroides B3 & $22.07 \pm 0.019$ & $22.044 \pm 0.366$ \\
\hline
\end{tabular}

TABLE 2: Proteins contents (\%) of different exopolysaccharides fractions.

\begin{tabular}{lcc}
\hline Strains & EPS-ETOH & EPS-UF \\
\hline Lc. Lactis SLT10 & $1.008 \pm 0.049$ & $1.284 \pm 0.048$ \\
Lb. plantarum C7 & $0.928 \pm 0.036$ & $0.414 \pm 0.027$ \\
Ln. mesenteroides B3 & $0.925 \pm 0.033$ & $0.808 \pm 0.067$ \\
\hline
\end{tabular}

purification. Similar results were found by Bergmaier et al. [16], who compared UF with a conventional method based on ethanol precipitation, dialysis, and protein removal by trichloroacetic acid; the EPS recovery by the UF was higher.

Higher EPS recovery $(70.38 \%)$ was, also, found by Pan and Mei [32] when using UF for the purification of EPS obtained from Lc. lactis subsp. lactis 12. Tuinier el al. [17] used UF with a polysulfone membrane (molar exclusion limit10 kDa) after a microfiltration step for the separation of EPSB40 from Lc. lactis subsp. cremoris on whey based media; the freeze-dried extract contains 63\% EPS.

Polysaccharides yields obtained in this work (Table 1) were low compared to literature. This result can be explained by the following: (i) both methods used are not appropriate to isolate EPS which affects strongly the final yield; (ii) EPS production by the three studied strains was limited in these culture conditions. Remada and Abraham [37] studied the effect of a heat treatment of the milk on EPS recovery and found that the highest recovery of EPS was obtained when samples were heated as a first step of isolation. The heat treatment allows the separation of polysaccharide attached to cells since that it has been shown that LAB express at least two distinct phenotypic forms of EPS, either ropy and/or capsular forms [38]. In the procedures without heat treatment, part of the polysaccharide attached to cells would be lost with pellet during broth culture centrifugation. Moreover, heat treatment inactivates the enzymes that could hydrolyze the polymer (glycohydrolases). Remada and Abraham [37] suggested also a method involving 1 or 2 steps of ethanol precipitation followed by dialysis with different cutoff membranes than TCA precipitation.

Proteins content of freeze-dried extracts for both methods was evaluated using Bradford's assay. Results are shown in Table 2.

The low proteins content (about 1\%) of all studied samples approves the efficiency of these methods to separate proteins from polysaccharides and to provide a high purity extracts. Similar results ( $1 \%$ of proteins) were found by Maalej et al. [39] for EPS22 extracted from Pseudomonas stutzeri AS22 by applying ultrafiltration followed by dialysis. Pan and Mei [32] indicated an absence of proteins and nucleic acid in the EPS-I extracted from Lc. lactis subsp. lactis 12 by ultrafiltration. Similar results were also found after the analysis of purified EPS sample from $L b$. plantarum YW11 using anion-exchange chromatography on DEAE-cellulose with $1.38 \pm 0.25 \%$ proteins content [40]. The proteins content of EPS from Leuconostoc sp. CFR 2181 extracted by Ice-cold isopropyl alcohol precipitation and washed with acetone was only $0.8 \%$ [41]. Tuinier el al. [17] obtained proteins content of $18 \%$ for Lc. lactis subsp. cremoris when grown on whey based media.

3.2. Monomer Composition and Molar Ratio of Exopolysaccharides. Different methods are available for determining the monomer composition of EPS samples. Methanolysis and per-trimethylsilylation provide samples that can be analyzed by GC. Hanko and Rohrer [42] proposed a simple method, requiring acid hydrolysis followed by monomer detection using high-pressure anion-exchange chromatography with pulsed amperometric detection.

In our work, monosaccharides composition of different polysaccharides fractions were determined according to Kamerling method [43] modified by par Montreuil [44]. Identification and quantification of monosaccharides began with a methanolysis of the polymer. The glycosidic residues are converted to their corresponding volatile trimethylsilyl derivatives and then analyzed by gas chromatography-flame ionization detector (GC-FID). The sugar composition and molar ratios of EPS-ETOH and EPS-UF extracts from the three studied strains are summarized in Table 3.

For SLT10, the main sugars were glucose (Glu) and mannose (Man) for EPS-ETOH in the molar ratio of 0.47:1, while (Glu), mannose (Man), and rhamnose (Rha) were present in EPS-UF in the molar ratio of 0.58:1:0.18. This result suggests that the strain produces heteropolysaccharides. Pan and Mei [32] showed that EPS-I extracted from L. lactis subsp. lactis 12 is mainly composed of fructose and rhamnose. According to literature, Lc. lactis subsp. lactis and Lc. lactis subsp. cremoris produce heteropolysaccharides. Lc. lactis subsp. cremoris B40 and Lc. lactis subsp. cremoris SBT 0495 produce an EPS composed of glucose, galactose, rhamnose, and phosphate at a ratio of 2:2:1:1 [11, 14]. This diversity in EPS composition produced by $L c$. lactis can be explained by genetic studies. Indeed, genes implicated in EPS production in Lc. lactis are encoded by plasmid DNA. The first lactococcal eps locus identified was that of Lc. lactis subsp. cremoris NIZO B40; it comprises 14 plasmid-encoded genes [45]. Since then, partial sequences of eps gene clusters have been identified in $L c$. lactis subsp. cremoris NIZO B891 and NIZO B35 strains [46]. Cluster consisting of 23 putative EPS biosynthetic determinants has been identified on plasmid pCI658 in $L c$. lactis subsp. cremoris $\mathrm{HO} 2$ [47].

GC-MS analysis of the monosaccharide composition of the EPS produced by $L b$. plantarum C7 showed that the EPS was composed of glucose and mannose in a molar ratio of 0.607:1 for EPS-ETOH and 4.07:1 for EPS-UF, which suggested that the strain produces heteropolysaccharides. Different monomers composition and proportion of $L b$. plantarum strains are available in the literature. The EPS purified from $L b$. plantarum YW11 using anion-exchange chromatography is composed of glucose and galactose in a 
TABLE 3: Sugar composition and molar ratio of exopolysaccharides isolated from the three studied strains (SLT10, C7, and B3).

\begin{tabular}{|c|c|c|c|c|c|}
\hline \multirow[t]{2}{*}{ Strains } & \multirow[t]{2}{*}{ Monomers } & \multicolumn{2}{|c|}{ Molar ratio } & \multicolumn{2}{|c|}{$\operatorname{Mol}(\%)$} \\
\hline & & EPS-ETOH & EPS-UF & EPS-ETOH & EPS-UF \\
\hline \multirow{4}{*}{ Lc. Lactococcus SLT10 } & Glucose & $0.47 \pm 0.033$ & $0.58 \pm 0.0001$ & $1.97 \pm 0.008$ & $8.46 \pm 0.35$ \\
\hline & Mannose & 1 & 1 & $4.15 \pm 0.27$ & $14.59 \pm 0.6$ \\
\hline & Rhamnose & - & $0.18 \pm 0.002$ & - & $2.48 \pm 0.13$ \\
\hline & Total & & & $6.13 \pm 0.264$ & $25.55 \pm 1.09$ \\
\hline \multirow{3}{*}{ Lb. plantarum C7 } & Glucose & $0.607 \pm 0.162$ & $4.07 \pm 0.82$ & $3.34 \pm 1.31$ & $13.36 \pm 8.11$ \\
\hline & Mannose & 1 & 1 & $6.01 \pm 3.77$ & $8.98 \pm 7.73$ \\
\hline & Total & & & $9.35 \pm 5.09$ & $22.34 \pm 2.73$ \\
\hline \multirow{3}{*}{ Ln. mesenteroides B3 } & Glucose & $0.61 \pm 0.02$ & $3.48 \pm 0.02$ & $1.97 \pm 0.167$ & $13.35 \pm .09$ \\
\hline & Mannose & 1 & 1 & $3.21 \pm 0.38$ & $3.85 \pm 0.62$ \\
\hline & Total & & & $5.19 \pm 0.54$ & $17.20 \pm 2.72$ \\
\hline
\end{tabular}

molar ratio of 2.71:1 [40]. EPS extracted from $L b$. plantarum KF5 presented a monomer composition of mannose, glucose, and galactose in a molar ratio of 1:4.99:6.90 [48]. Li et al. [49] showed that the strain Lb. plantarum 70810 isolated from Chinese paocai produced two types of EPS with a monomer composition of glucose, mannose, and galactose in a molar ratio of 18.21:78.76:3.03 and 12.92:30.89:56.19, respectively. Indeed, the monosaccharide composition of EPS produced by LAB can be affected by the type of strains; Laws et al. [8] revealed that the genes coding for EPS synthesis are of plasmid origin in the mesophilic LAB strains (e.g., Lactococcus), but they are chromosomally based in the thermophilic strains (Streptococcus and Lactobacilli). In general, the EPS-producing ability of LAB is regarded as being unstable. For mesophilic LAB strains, the unstable nature of EPS synthesis is consistent with the genes for EPS synthesis being plasmid bound. For the thermophilic LAB strains, it has been proposed that the loss of EPS-producing character is due to deletions and rearrangement resulting from genetic instability.

For Ln. mesenteroides B3, GC analysis showed a monomeric composition of glucose and mannose in a molar ratio of 0.61:1 for EPS-ETOH and 3.48:1 for EPS-UF. Even though, Leuconostocs are well known for the production of homopolysaccharides such as alternan, dextran, and levan from sucrose metabolism [50], the strain Leuconostoc mesenteroides B3 produces a heteropolysaccharide composed of glucose and mannose. Indeed, Welman and Maddox [51] revealed that themesophilic $\mathrm{LAB}$ such as Leuconostoc mesenteroides also produces heteropolysaccharides. Previous study showed the ability of Leuconostocs to produce heteropolysaccharides; the EPS isolated from Leuconostoc sp. CFR 2181 consisted mainly of glucose (91\%) with minor quantities of rhamnose and arabinose [41].

Based on Table 3, the main observation was the difference in monomer composition of EPS extracted by ultrafiltration and ethanol precipitation for Lc. lactis SLT10. Moreover, for the strains $L b$. plantarum C7 and Ln. mesenteroides B3 when comparing both purification methods and in spite of similarity in monomer composition, the molar ratios were different.
This result can be explained by the hypothesis that when sucrose was used as carbon source, the studied strains synthesize mixtures of EPSs. The EPSs can have different structures (different monomeric composition) in the case of the strain SLT10 or different molar ratios with the same monomers for Lb. plantarum C7 and Ln. mesenteroides B3. Thus, we can suggest that the strain SLT10 produces at least two types of exopolysaccharides with different molecular weight and different monomeric composition: the first one with the higher molecular weight is composed of glucose and mannose and the second one with lower molecular weight probably contains rhamnose. When ultrafiltration is used as purification method, with a $10 \mathrm{kDa}$ cut-off membrane that could retain either high- and low-molecular weight polysaccharides, both EPSs were retained. However for ethanol precipitation only one EPS was precipitated; probably the one with the higher molecular weight composed of glucose and mannose.

For the strains $\mathrm{Lb}$. plantarum $\mathrm{C} 7$ and Ln. mesenteroides $\mathrm{B} 3$, there is also the possibility of recovering EPS samples that have identical structure (glucose and mannose) but different molecular masses. In previous studies Comte et al. [20] have showed that the EPS characteristics present qualitative and quantitative differences depending on the method used. They found that the extraction methods using chemical reagents strongly affected the HPSEC (high-pressure size exclusion chromatography) fingerprints of EPS, whereas the physical methods influenced only molecular weight distribution but not HPSEC fingerprints. It had been shown that Lactobacillus spp. G-77 produces two homopolysaccharides with different structures [52] (Duenas-Chasco et al., 1998). Degeest and de Vuyst [53] reported the production of a high-molecular mass and a low-molecular mass EPS by Streptococcus thermophilus LY03. The production of two polysaccharides by $L b$. rhamnosus has been reported [54]. A strain of Lb. reuteri LB 121 is able to produce two types of homopolysaccharides mainly composed of D-glucose or D-fructose [55].

3.3. Molecular Mass Estimation. The molecular mass of different EPSs isolated from the three studied strains with both methods was estimated using high-performance size 
TABLE 4: Molecular weight (Mw), molecular number (Mn), and polydispersity index of EPSs extracted from the three studied stains.

\begin{tabular}{lccccc}
\hline Purification method & Strains & Mw (kDa) & Mn (kDa) & Polydispersity Index (Mw/Mn) & Mass recovery (\%) \\
\hline \multirow{3}{*}{ EPS-ETOH } & Lc. lactis SLT10 & $62.4 \pm 2.94$ & $19.3 \pm 2.07$ & $3.231 \pm 0.47$ & 37.3 \\
& Lb. plantarum C7 & $33.7 \pm 2.89$ & $8.5 \pm 3.44$ & $3.968 \pm 1.64$ & 46.0 \\
& Ln. mesenteroides B3 & - & - & - & - \\
\hline \multirow{3}{*}{ EPS-UF } & Lc. lactis SLT10 & $51.5 \pm 1.75$ & $12.3 \pm 1.38$ & $4.178 \pm 0.49$ & 54.6 \\
& Lb. plantarum C7 & $11.6 \pm 1.83$ & $2.1 \pm 0.95$ & $5.586 \pm 2.66$ & 53.5 \\
& Ln. mesenteroides B3 & $18.6 \pm 2.21$ & $8.4 \pm 1.52$ & $2.204 \pm 0.407$ & 46.1 \\
\hline
\end{tabular}

exclusion chromatography (HPSEC). The molecular weight distribution of EPS-UF and EPS-ETOH fractions of $L b$. plantarum C7, Lc. lactis SLT10, and Ln. mesenteroides B3 is presented in Figures 1 and 2.

Molecular weight $(\mathrm{Mw})$, molecular number $(\mathrm{Mn})$, and polydispersity index of EPSs isolated from the three studied stains are summarized in Table 4.

The result showed that the three strains present different EPS molecular masses. Indeed, the molar mass of the EPS produced by $\mathrm{LAB}$ varied according to strains and polymer type [6]. Generally, the EPSs produced by the bacterial strains in MRS-sucrose media are lower-molecular-mass fractions, whose molecular masses do not exceed $62.4 \pm 2.94 \mathrm{kDa}$. The MW of EPS extracted from Lc. lactis SLT 10 was the highest with both purification methods $(62.4 \pm 2.94 \mathrm{kDa}$ and $51.5 \mathrm{kDa} \pm 1.75)$. Heteropolysaccharides ranged from 40 to $9000 \mathrm{kDa}$ for Streptococcus thermophilus strains and 100 to $2000 \mathrm{kDa}$ for Lc. lactis spp. cremoris strains [6].

The molecular mass of the EPS produced by $L b$. plantarum C7 was determined to be $33.5 \pm 2.89 \mathrm{kDa}$ (EPS-ETOH) and $11.6 \pm 1.83 \mathrm{kDa}$ (EPS-UF) which was similar to that (44 kDa) of the EPS of L. plantarum EP56 [56] but lower than that $(110 \mathrm{kDa})$ of the EPS of Lactobacillus plantarum YW11 [40] and $(1150 \mathrm{kDa})$ of the EPS of Lb. plantarum C88 [57].

The molecular mass of EPS purified from Ln. mesenteroides B3 was only available for EPS-UF and was $18.6 \pm 2.21 \mathrm{kDa}$ which in the same range of magnitude of those reported for the EPS fractions of Leuconostoc sp. CFR 2181 with molecular weights ranging from $10 \mathrm{kDa}$ to $1500 \mathrm{kDa}$ [41].

The polydispersity index Mw/Mn (Mw, weight-average; $\mathrm{Mn}$, number-average), which reflects the degree of heterogeneity of the polymer's chain lengths, is ranging from $2.204 \pm 0.407$ to $5.586 \pm 2.66(>1)$ which represents a heterogeneous populations in terms of polysaccharide chains size. The lower polydispersity index value was obtained for the EPS fraction purified from $\mathrm{Ln}$. mesenteroides B3 $(2.204 \pm 0.407)$ which can be considered as moderately polydisperse distribution type even when the EPS fractions purified from $L c$. lactis SLT10 and Lb. plantarum C7 were considered as broadly polydisperse distribution type.

The results from Table 4 show two mains observations: (i) EPS-ETOH fractions molecular weights were higher than those of EPS-UF fractions and (ii) the heterogeneity of EPS fractions is more pronounced when UF was used as purification method (polydispersity index ranged from $4.178 \pm 0.49$ to $5.586 \pm 2.66)$.
These observations can be explained by the hypothesis given above that the studied strains grown in MRS-sucrose produce more than one polymer with various molecular masses causing the heterogeneity of the freeze-dried extracts (high polydispersity index). This hypothesis could explain variations in monomer composition and molecular ratios of EPS-ETOH and EPS-UF. When using UF as purification methods, polymers produced by the lactic strains remain in the retentate. However, when using ethanol for purification, only one polymer precipitates (probably the one with the highest molecular weight). Grobben et al. [15] found that $L b$. bulgaricus strain NCFB 2772, grown in chemically defined medium, produced two EPS fractions with molecular masses of 40 and $1700 \mathrm{kDa}$. Similar results were reported with $L c$. Lactis subsp. cremoris LC 330 [13].

3.4. The Structural Characterization of the Purified EPS. FTIR spectroscopy has been a powerful and valuable analytical method to investigate the nature of the functional groups of EPS in terms of monomeric units and their linkages. Figure 3 shows the FTIR spectra of EPS fractions from $L b$. plantarum C7, Lc. lactis SLT10, and Ln. mesenteroides B3 obtained by precipitation in a final ethanol concentration $96 \%$.

The spectrum of purified EPS was studied in the region between $400 \mathrm{~cm}^{-1}$ and $4000 \mathrm{~cm}^{-1}$ and showed numerous peaks from $3434 \mathrm{~cm}^{-1}$ to $534 \mathrm{~cm}^{-1}$. In comparison with the IR spectra of polysaccharides listed in the literature, all the peaks obtained were in agreement with the typical absorption peaks of polysaccharides.

As can be seen, no significant difference in the main absorption intensity was observed among the three fractions. However, upon close comparison of the spectra, small differences are observed.

The broad absorption peak observed at around 3434$3420 \mathrm{~cm}^{-1}$ indicated the presence of intensive hydroxyl groups $(\mathrm{O}-\mathrm{H})$ stretching frequency confirming the polysaccharide nature of the material [58]. The $\mathrm{C}-\mathrm{H}$ stretching vibration gives signals between 2928 and $2850 \mathrm{~cm}^{-1}$ [59]. The peak observed around $2366 \mathrm{~cm}^{-1}$ is attributed to $\mathrm{O}-\mathrm{H}$ bond groups, which could be explained by their carbohydrate nature.

The absorption peaks at $1634 \mathrm{~cm}^{-1}, 1628 \mathrm{~cm}^{-1}$, and $1626 \mathrm{~cm}^{-1}$ were due to the stretch vibration of carboxyl group $(\mathrm{C}=\mathrm{O})[60]$. The absorption at 1404 and $1406 \mathrm{~cm}^{-1}$ was due to the symmetric stretching of $-\mathrm{COO}$.

There were peaks near $1000-1200 \mathrm{~cm}^{-1}$, indicating that the polysaccharide contained $\alpha$-pyranose. Indeed, the 


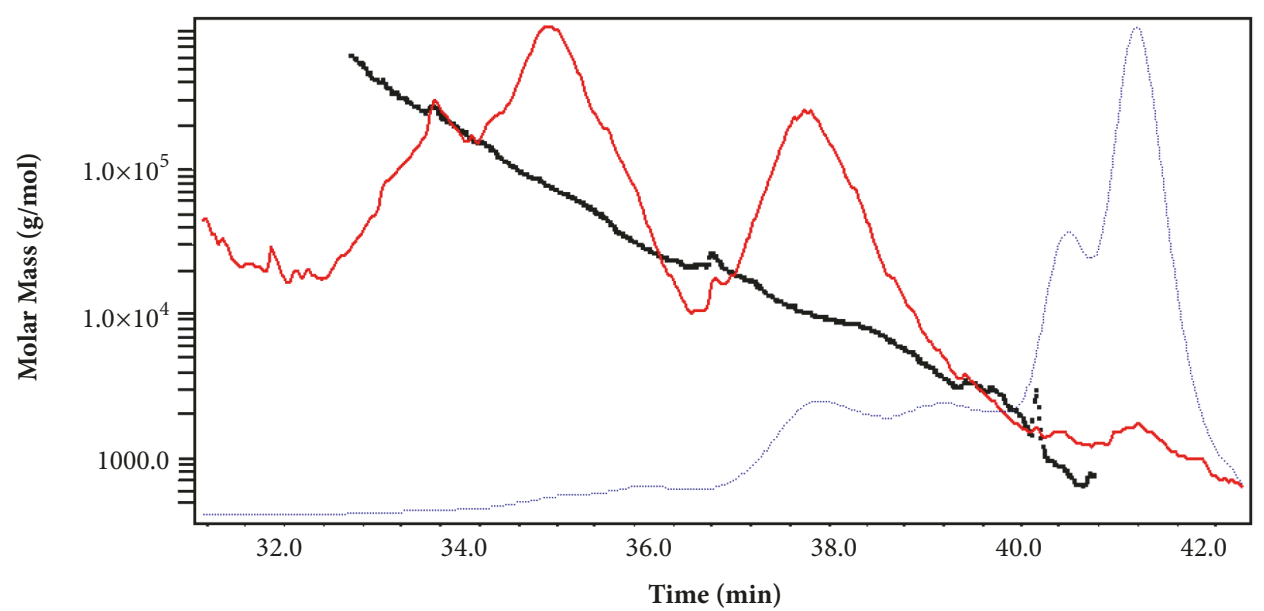

(a)

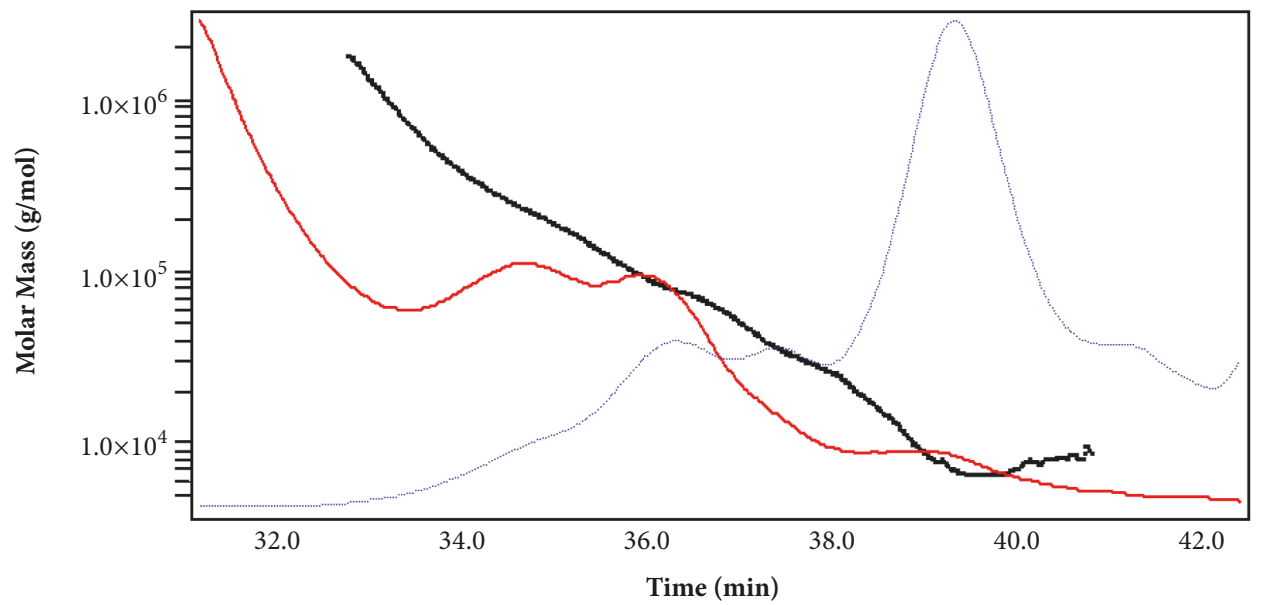

(b)

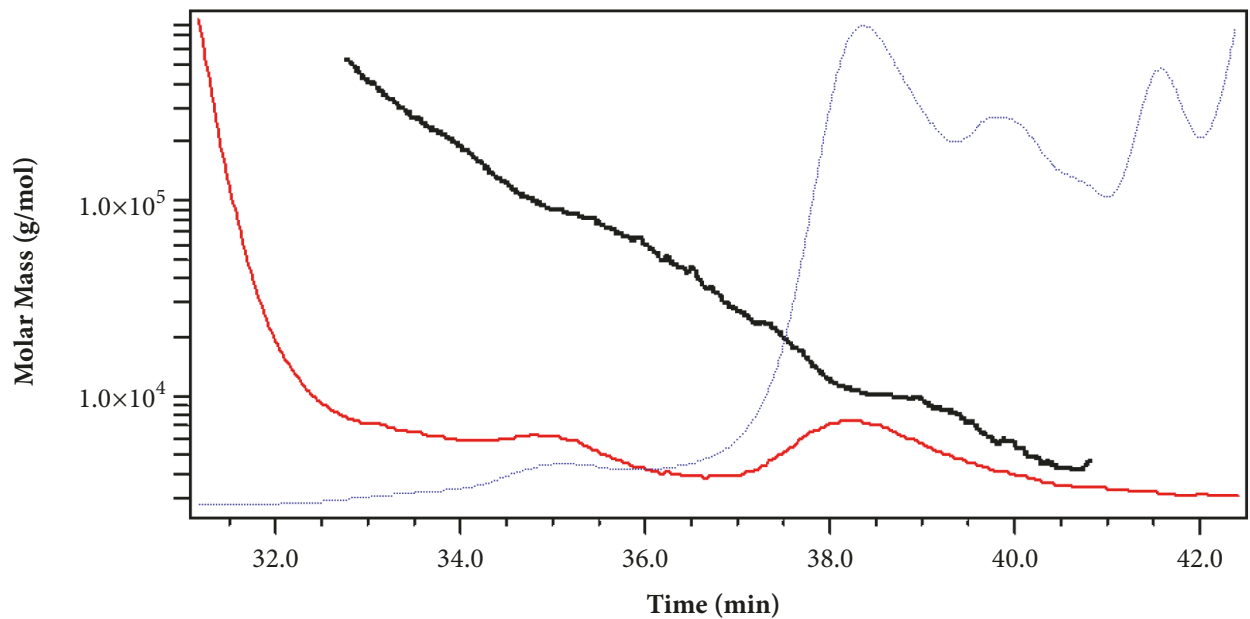

(c)

FIgURE 1: The molecular weight distribution of EPS-UF fractions of Lb. plantarum C7 (a), Lc. lactis SLT10 (b), and Ln. mesenteroides B3 (c) (black squares: molar mass; red dashed line: LS (laser-light scattering); blue dotted line: RI (refractive index)). 


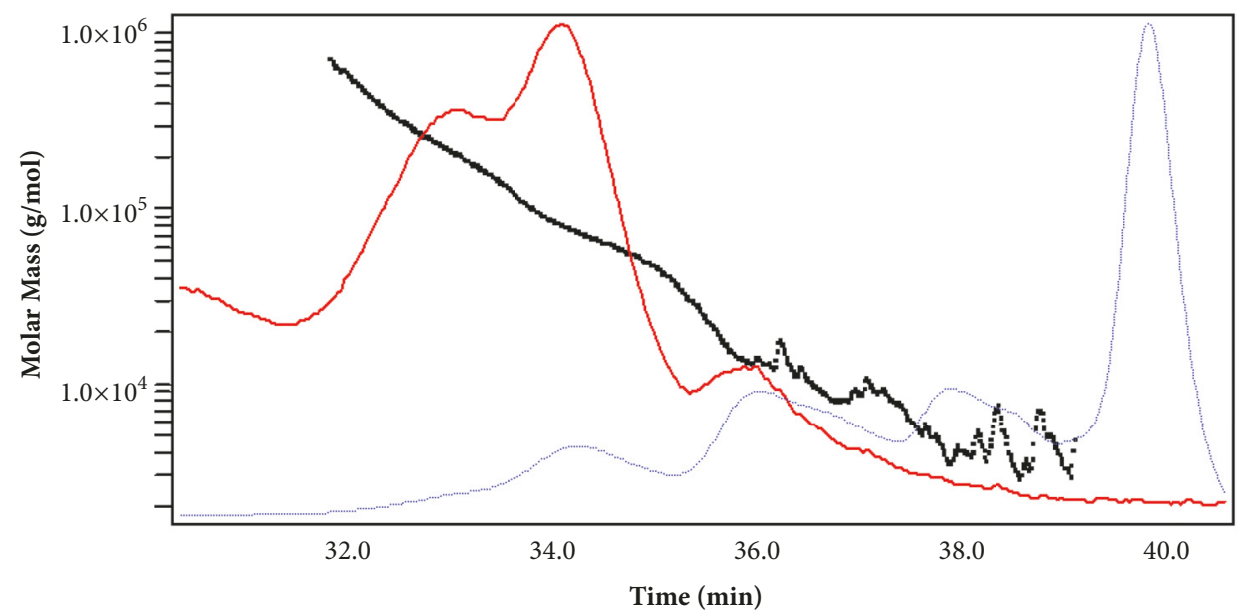

(a)

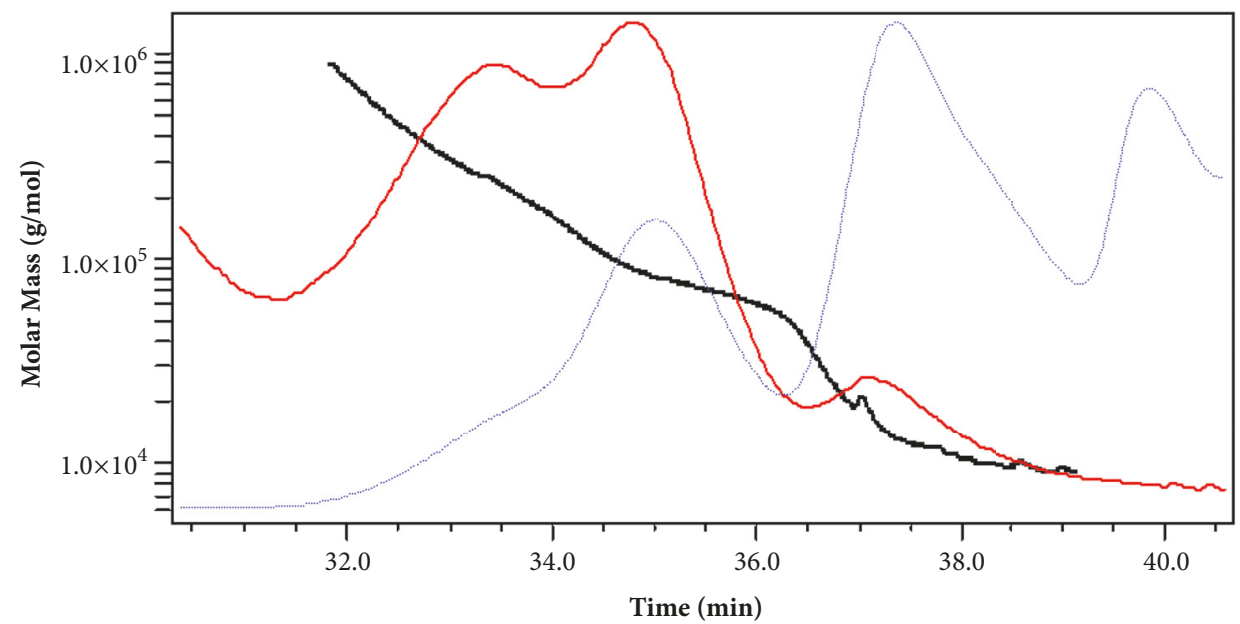

(b)

Figure 2: The molecular weight distribution of EPS-ETOH fractions of Lb. plantarum C7 (a) and Lc. lactis SLT10 (b) (black squares: molar mass; red dashed line: LS (laser-light scattering); and blue dotted line: RI (refractive index)).

carbohydrates show high absorbencies in this region, which is within the so-called fingerprint region, where the position and the intensity of the bands are specific for every polysaccharide, allowing its possible identification [61].

The intense peaks at $1094 \mathrm{~cm}^{-1}, 1074 \mathrm{~cm}^{-1}$, and $1048 \mathrm{~cm}^{-1}$ were attributed to the vibration of the glycosidic linkage $\mathrm{C}-\mathrm{O}$ C of glucose [60].

Along with these peaks, more characteristic peaks at 870 and $804 \mathrm{~cm}^{-1}$ region were also detected indicating that the EPS contained both $\alpha$ and $\beta$-type glycosidic linkages between sugar monomers [62]. These peaks are absent in the EPS fraction extracted from $L n$. mesenteroides B3.

The weak adoption band at $534-538 \mathrm{~cm}^{-1}$, absent in the EPS fraction purified from Ln. mesenteroides B3, was indicative of glycosidic linkage peak for polysaccharide.

\section{Conclusion}

In this work, ultrafiltration and ethanol precipitation were used for the purification of EPSs produced by three
Lactic Acid Bacteria strains isolated from different Tunisian biotopes. Results confirmed that EPS recovery by ultrafiltration was significantly higher than ethanol precipitation for Lc. lactis SLT10 and Lb. plantarum C7. GC-MS and HPSEC analysis of EPSs showed that the three studied strains produce a heteropolysaccharides with low-molecular masses. Depending on purification method, the monomeric composition and molar ratios of the different EPS fractions are affected.

\section{Data Availability}

The data used to support the findings of this study are available from the corresponding author upon request.

\section{Conflicts of Interest}

The authors declare that they have no conflicts of interest. 


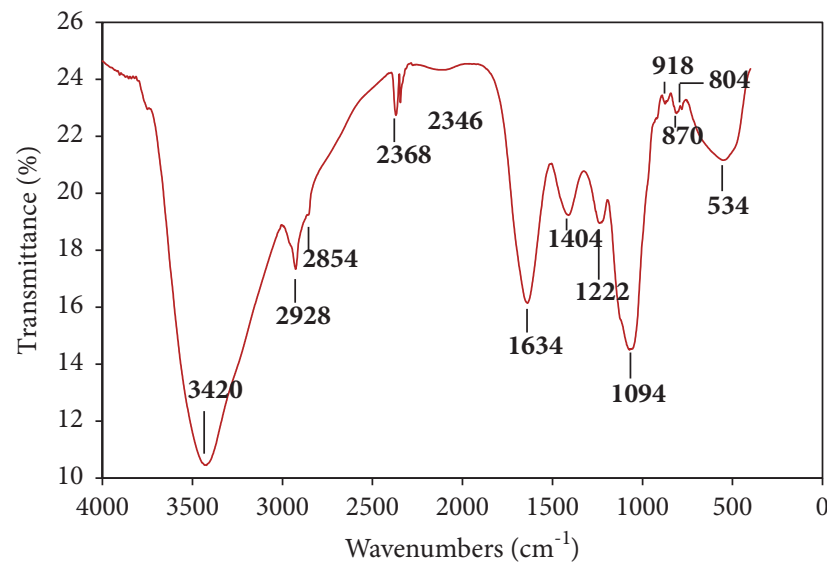

(a)

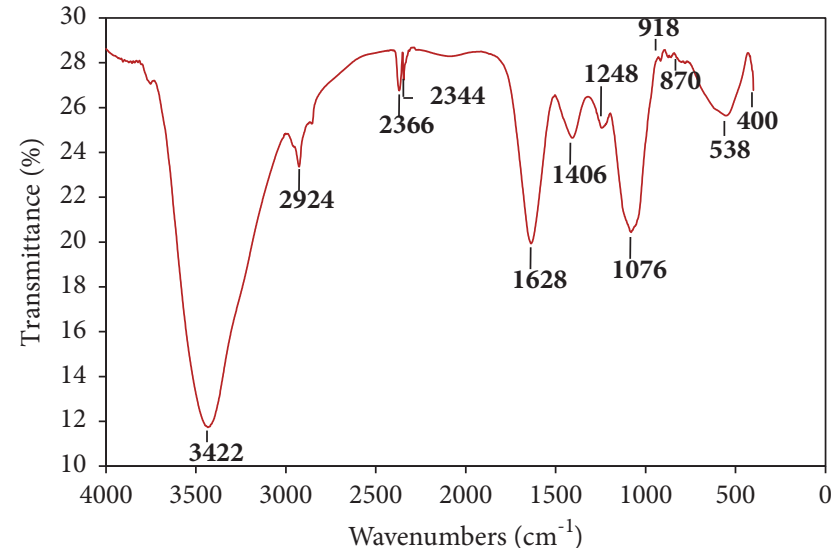

(b)

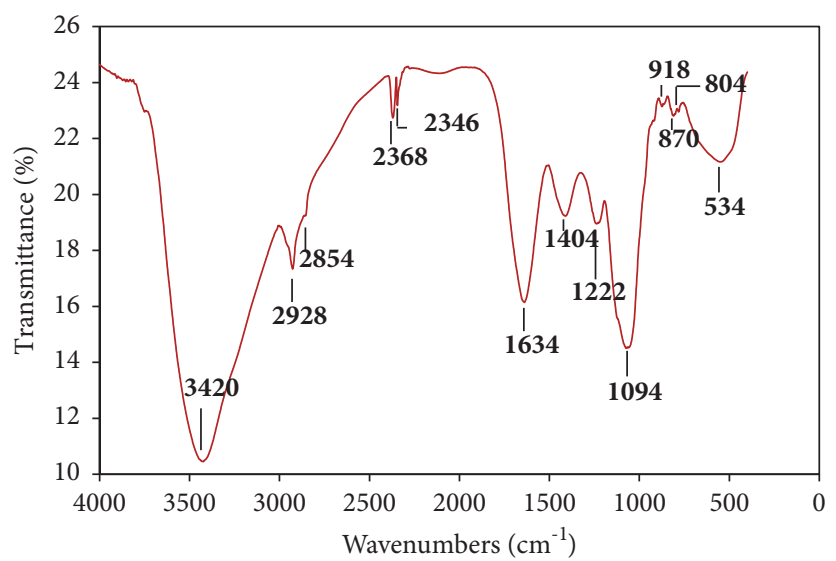

(c)

FIGURE 3: FTIR spectra of EPS-ETOH fractions of Lb. plantarum C7 (a), Lc. lactis SLT10, (b) and Ln. mesenteroides B3 (c).

\section{Acknowledgments}

This work was supported by Research Grant "SSHN" from French Institute of Cooperation, Tunis, Tunisia.

\section{References}

[1] C. Liu, J. Lu, L. Lu, Y. Liu, F. Wang, and M. Xiao, "Isolation, structural characterization and immunological activity of an exopolysaccharide produced by Bacillus licheniformis 8-37-01," Bioresource Technology, vol. 101, no. 14, pp. 5528-5533, 2010.

[2] S. Ye, F. Liu, J. Wang, H. Wang, and M. Zhang, "Antioxidant activities of an exopolysaccharide isolated and purified from marine Pseudomonas PF-6," Carbohydrate Polymers, vol. 87, no. 1, pp. 764-770, 2012.

[3] J. Cerning, "Exocellular polysaccharides produced by lactic acid bacteria," FEMS Microbiology Letters, vol. 87, no. 1-2, pp. 113-130, 1990.

[4] P. Ruas-Madiedo, J. Hugenholtz, and P. Zoon, "An overview of the functionality of exopolysaccharides produced by lactic acid bacteria," International Dairy Journal, vol. 12, pp. 163-171, 2002.

[5] S. Badel, T. Bernardi, and P. Michaud, "New perspectives for Lactobacilli exopolysaccharides," Biotechnology Advances, vol. 29, no. 1, pp. 54-66, 2011.
[6] P. Ruas-Madiedo and C. G. de los Reyes-Gavilán, "Invited review: methods for the screening, isolation, and characterization of exopolysaccharides produced by lactic acid bacteria," Journal of Dairy Science, vol. 88, no. 3, pp. 843-856, 2005.

[7] L. De Vuyst, F. De Vin, F. Vaningelgem, and B. Degeest, "Recent developments in the biosynthesis and applications of heteropolysaccharides from lactic acid bacteria," International Dairy Journal, vol. 11, no. 9, pp. 687-707, 2001.

[8] A. Laws, Y. Gu, and V. Marshall, "Biosynthesis, characterisation, and design of bacterial exopolysaccharides from lactic acid bacteria," Biotechnology Advances, vol. 19, no. 8, pp. 597-625, 2001.

[9] P. J. Looijesteijn and J. J. Hugenholtz, "Uncoupling of growth and exopolysaccharide production by Lactococcus lactis subsp. cremoris NIZO B40 and optimization of its synthesis," Journal of Bioscience and Bioengineering, vol. 88, no. 2, pp. 178-182, 1999.

[10] M. Higashimura, B. W. Mulder-Bosman, R. Reich, T. Iwasaki, and G. W. Robijn, "Solution properties of viilian, the exopolysaccharide from Lactococcus lactis subsp. cremoris SBT 0495," Biopolymer, vol. 45, no. 2, pp. 43-58, 2000.

[11] H. Nakajima, T. Hirota, T. Toba, T. Itoh, and S. Adachi, "Structure of the extracellular polysaccharide from slime-forming Lactococcus lactis subsp. cremoris SBT 0495," Carbohydrate Research, vol. 224, pp. 245-253, 1992. 
[12] Z. Yang, E. Huttunen, M. Staaf, G. Widmalm, and T. Heikki, "Separation, purification and characterisation ofextracellular polysaccharides produced by slime-forming Lactococcus lactis subsp. cremoris strains," International Dairy Journal, vol. 9, pp. 631-638, 1999.

[13] V. M. Marshall, E. N. Cowie, and R. S. Moreton, "Analysis and Production of 2 Exopolysaccharides from Lactococcus-Lactis subsp. cremoris Lc330," Journal of Dairy Research, vol. 62, pp. 621-628, 1995.

[14] W. H. M. Van Casteren, C. Dijkema, H. A. Schols, G. Beldman, and A. G. J. Voragen, "Characterisation and modification of the exopolysaccharide produced by Lactococcus lactis subsp. cremoris B40," Carbohydrate Polymers, vol. 37, no. 2, pp. 123130, 1998.

[15] G. J. Grobben, W. H. van Casteren, H. A. Schols et al., "Analysis of the exopolysaccharides produced by Lactobacillus delbrueckii subsp. bulgaricus NCFB 2772 grown in continuous culture on glucose and fructose," Applied Microbiology and Biotechnology, vol. 48, no. 4, pp. 516-521, 1997.

[16] D. Bergmaier, C. Lacroix, M. G. Macedo, and P. Champagne, "New method for exopolysaccharide determination in culture broth using stirred ultrafiltration cells," Applied Microbiology and Biotechnology, vol. 57, pp. 401-406, 2001.

[17] R. Tuinier, P. Zoon, C. Olieman, M. A. C. Stuart, G. J. Fleer, and C. G. De Kruif, "Isolation and physical characterization of an exocellular polysaccharide," Biopolymers, vol. 49, no. 1, pp. 1-9, 1999.

[18] F. Levander, M. Svensson, and P. Rådström, "Small-scale analysis of exopolysaccharides from Streptococcus thermophilus grown in a semi-defined medium," BMC Microbiology, vol. 1, no. 1, pp. 1-23, 2001.

[19] L. Zhang, J. Zhou, G. Yang, and J. Chen, "Preparative fractionation of polysaccharides by columns packedwith regenerated cellulose gels," Journal of Chromatography A, vol. 816, pp. 131136, 1998.

[20] S. Comte, G. Guibaud, and M. Baudu, "Relations between extraction protocols for activated sludge extracellular polymeric substances (EPS) and EPS complexation properties: Part I. Comparison of the efficiency of eight EPS extraction methods," Enzyme and Microbial Technology, vol. 38, no. 1-2, pp. 237-245, 2006.

[21] L. Domínguez, M. Rodríguez, and D. Prats, "Effect of different extraction methods on bound EPS from MBR sludges. Part I: Influence of extraction methods over three-dimensional EEM fluorescence spectroscopy fingerprint," Desalination, vol. 261, no. 1-2, pp. 19-26, 2010.

[22] I. Bourven, E. Joussein, and G. Guibaud, "Characterisation of the mineral fraction in extracellular polymeric substances (EPS) from activated sludges extracted by eight different methods," Bioresource Technology, vol. 102, no. 14, pp. 7124-7130, 2011.

[23] P. D’Abazac, F. Bordas, E. Joussein, E. D. van Hullebusch, P. N. Lens, and G. Guibaud, "Metal binding properties of extracellular polymeric substances extracted from anaerobic granular sludges," Environmental Science and Pollution Research, vol. 20, no. 7, pp. 4509-4519, 2013.

[24] J. P. L. Kenney and J. B. Fein, "Importance of extracellular polysaccharides on proton and Cd binding to bacterial biomass: A comparative study," Chemical Geology, vol. 286, pp. 109-117, 2011.

[25] W. Chen, W.-P. Wang, H.-S. Zhang, and Q. Huang, "Optimization of ultrasonic-assisted extraction of water-soluble polysaccharides from Boletus edulis mycelia using response surface methodology," Carbohydrate Polymers, vol. 87, no. 1, pp. 614-619, 2012.

[26] W. C. Zeng, Z. Zhang, H. Gao, L. R. Jia, and W. Y. Chen, "Characterization of antioxidant polysaccharides from Auricularia auricular using microwave-assisted extraction," Carbohydrate Polymers, vol. 89, no. 2, pp. 694-700, 2012.

[27] M. Palanisamy, L. Aldars-García, A. Gil-Ramírez et al., "Pressurized water extraction of $\beta$-glucan enriched fractions with bile acids-binding capacities obtained from edible mushrooms," Biotechnology Progress, vol. 30, no. 2, pp. 391-400, 2014.

[28] M. Ziadi, Y. Touhami, M. Achour, P. Thonart, and M. Hamdi, "The effect of heat stress on freeze-drying and conservation of Lactococcus," Biochemical Engineering Journal, vol. 24, no. 2, pp. 141-145, 2005.

[29] T. Bouzaine, T. Elmajdoub, P. H. Thonart, and M. Hamdi, "Selection de bactéries lactiques probiotiques d'origine animale," Microbiologie et Hygiène Alimentaire, vol. 46, pp. 24-29, 2004.

[30] M. Ziadi, S. Mhir, N. Kbaier, M. Hamdi, and A. Ferchichi, "Microbiological analysis and screening of lactic acid bacteria from Tunisian date palm sap," African Journal of Microbiology Research, vol. 5, no. 19, pp. 2929-2935, 2011.

[31] I. Trabelsi, S. Ben Sliman, H. Chaabane, and R. Ben Salah, "Purification and characterization of a novel exopolysaccharides produced by Lactobacillus sp. Ca 6 ", International Journal of Biological Macromolecules, vol. 74, pp. 541-546, 2015.

[32] D. Pan and X. Mei, "Antioxidant activity of an exopolysaccharide purified from Lactococcus lactis subsp. lactis 12," Carbohydrate Polymers, vol. 80, no. 3, pp. 908-914, 2010.

[33] X. Feng, Y. Jianming, T. Tesfaye, D. Floyd, and W. Donghai, "Qualitative and quantitative analysis of lignocellulosic biomass using infrared techniques: A mini-review," Applied Energy, vol. 104, pp. 801-809, 2013.

[34] E. Wiercigroch, E. Szafraniec, K. Czamara et al., "Raman and infrared spectroscopy of carbohydrates: A review," Spectrochimica Acta Part A: Molecular and Biomolecular Spectroscopy, vol. 185, pp. 317-335, 2017.

[35] M. Dubois, K. A. Gilles, J. K. Hamilton, P. A. Rebers, and F. Smith, "Colorimetric method for determination of sugars and related substances," Analytical Chemistry, vol. 28, pp. 350-356, 1956.

[36] M. M. Bradford, "A rapid and sensitive method for the quantitation of microgram quantities of protein utilizing the principle of protein-dye binding," Analytical Biochemistry, vol. 72, no. 1-2, pp. 248-254, 1976.

[37] P. S. Rimada and A. G. Abraham, "Comparative study of different methodologiesto determine the exopolysaccharide produced by kefir grains in milk and whey," Le Lait, vol. 83, pp. 97-87, 2003.

[38] E. Knoshaug, J. A. Ahlgren, and J. E. Trempy, "Growth associated exopolysaccharide expression in Lactococcus lactis subspecies cremoris Ropy352," Journal of Dairy Science, vol. 83, no. 4, pp. 633-640, 2000.

[39] H. Maalej, C. Boisset, N. Hmidet, L. Buon, A. Heyraud, and M. Nasri, "Purification and structural data of a highly substituted exopolysaccharide from Pseudomonas stutzeri AS22," Carbohydrate Polymers, vol. 112, pp. 404-411, 2014.

[40] J. Wang, X. Zhao, Z. Tian, Y. Yang, and Z. Yang, "Characterization of an exopolysaccharide produced by Lactobacillus plantarum YW11 isolated from Tibet Kefir," Carbohydrate Polymers, vol. 125, pp. 16-25, 2015. 
[41] S. V. N. Vijayendra, G. Palanivel, S. Mahadevamma, and R. N. Tharanathan, "Physico-chemical characterization of an exopolysaccharide produced by a non-ropy strain of Leuconostoc sp. CFR 2181 isolated from dahi, an Indian traditional lactic fermented milk product," Carbohydrate Polymers, vol. 72, no. 2, pp. 300-307, 2008.

[42] V. P. Hanko and J. S. Rohrer, "Determination of carbohydrates, sugar alcohols, and glycols in cell cultures and fermentation broths using high-performance anion-exchange chromatography with pulsed amperometric detection," Analytical Biochemistry, vol. 283, no. 2, pp. 192-199, 2000.

[43] J. P. Kamerling, G. J. Gerwig, J. F. Vliegenthart, and J. R. Clamp, "Characterization by gas-liquid chromatography-mass spectrometry and proton-magnetic-resonance spectroscopy of pertrimethylsilyl methyl glycosides obtained in the methanolysis of glycoproteins and glycopeptides," Biochemical Journal, vol. 151, no. 3, pp. 491-495, 1975.

[44] J. Montreuil, S. Bouquelet, H. Debray, B. Fournet, G. Spik, and G. Strecker, "Glycoproteins," in Carbohydrate Analysis: A Practical Approach, M. F. Chaplin and J. F. Kennedy, Eds., pp. 143-204, Oxford University press, New York, NY, USA, 1986.

[45] R. van Kranenburg, J. D. Marugg, van Swam II, N. J. Willem, and W. M. de Vos, "Molecular characterization of the plasmidencoded eps gene cluster essential for exopolysaccharide biosynthesis in Lactococcus lactis," Molecular Microbiology, vol. 24, no. 2, pp. 387-397, 1997.

[46] R. van Kranenburg, I. I. van Swam, J. D. Marugg, M. Kleerebezem, and W. M. de Vos, "Exopolysaccharide Biosynthesis in Lactococcus lactis NIZO B40: Functional Analysis of the Glycosyltransferase Genes Involved in Synthesis of the Polysaccharide Backbone," Journal of Bacteriology, vol. 181, no. 1, pp. 338-340, 1999.

[47] A. Forde and G. F. Fitzgerald, "Molecular organization of exopolysaccharide (EPS) encoding genes on the lactococcal bacteriophage adsorption blocking plasmid, pCI658," Plasmid, vol. 49, no. 2, pp. 130-142, 2003.

[48] Y. Wang, C. Li, P. Liu, Z. Ahmed, P. Xiao, and X. Bai, "Physical characterization of exopolysaccharide produced by Lactobacillus plantarum KF5 isolated from Tibet Kefir," Carbohydrate Polymers, vol. 82, no. 3, pp. 895-903, 2010.

[49] C. Li, W. Li, X. Chen et al., "Microbiological, physicochemical and rheological properties of fermented soymilk produced with exopolysaccharide (EPS) producing lactic acid bacteria strains," LWT - Food Science and Technology, vol. 57, no. 2, pp. 477-485, 2014.

[50] GL. Cote, J. Ahlgren, and A. Kirk-Othmer, Microbial polysaccharides, in Encyclopedia of chemical technology, John Wiley and Sons Inc, New York, NY, USA, 4th edition, 1995.

[51] A. D. Welman and I. S. Maddox, "Exopolysaccharides from lactic acid bacteria: perspectives and challenges," Trends in Biotechnology, vol. 21, no. 6, pp. 269-274, 2003.

[52] M. T. Dueñas-Chasco, M. A. Rodríguez-Carvajal, P. TejeroMateo, J. L. Espartero, A. Irastorza-Iribas, and A. M. GilSerrano, "Structural analysis of the exopolysaccharides produced by Lactobacillus spp. G-77," Carbohydrate Research, vol. 307, no. 1-2, pp. 125-133, 1998.

[53] B. Degeest and L. De Vuyst, "Indication that the Nitrogen Source Influences Both Amount and Size of Exopolysaccharides Produced by Streptococcus thermophilus LY03 and Modelling of the Bacterial Growth and Exopolysaccharide Production in a Complex Medium," Applied and Environmental Microbiology, vol. 65, no. 7, pp. 2863-2870, 1999.
[54] P. L. Pham, I. Dupont, D. Roy, G. Lapointe, and J. Cerning, "Production of Exopolysaccharide by Lactobacillus rhamnosus $\mathrm{R}$ and Analysis of Its Enzymatic Degradation during Prolonged Fermentation," Applied and Environmental Microbiology, vol. 66, no. 6, pp. 2302-2310, 2000.

[55] G. H. Van Geel-Schutten, E. J. Faber, E. Smit et al., "Biochemical and Structural Characterization of the Glucan and Fructan Exopolysaccharides Synthesized by the Lactobacillus reuteri Wild-Type Strain and by Mutant Strains," Applied and Environmental Microbiology, vol. 65, no. 7, pp. 3008-3014, 1999.

[56] R. Tallon, P. Bressollier, and M. C. Urdaci, "Isolation and characterization of two exopolysaccharides produced by Lactobacillus plantarum EP56," Research in Microbiology, vol. 154, no. 10, pp. 705-712, 2003.

[57] L. Zhang, C. Liu, D. Li, Y. Zhao, X. Zhang, and X. Zeng, "Antioxidant activity of an exopolysaccharide isolated from Lactobacillus plantarum C88," International Journal of Biological Macromolecules, vol. 54, pp. 270-275, 2013.

[58] J. Wang, H. Ai, and Liu M., "Enhanced welan gum production using cane molasses as substrate by Alcaligenes sp. ATCC31555," New Biotechnology, vol. 31, p. s40, 2014.

[59] M. R. S. Melo, J. P. A. Feitosa, A. L. P. Freitas, and R. C. M. De Paula, "Isolation and characterization of soluble sulfated polysaccharide from the red seaweed Gracilaria cornea," Carbohydrate Polymers, vol. 49, no. 4, pp. 491-498, 2002.

[60] S. Ye, M. Zhang, H. Yang et al., "Biosorption of $\mathrm{Cu} 2+, \mathrm{Pb} 2+$ and $\mathrm{Cr} 6+$ by a novel exopolysaccharide from Arthrobacter ps5," Carbohydrate Polymers, vol. 101, pp. 50-56, 2014.

[61] Z. Chi, Su. CD, and Lu. WD, "A new exopolysaccharide produced by marine Cyanothece sp. 113," Bioresource Technology, vol. 98, no. 6, pp. 1329-1332, 2007.

[62] O. Braissant, A. W. Decho, K. M. Przekop et al., "Characteristics and turnover of exopolymeric substances in a hypersaline microbial mat," FEMS Microbiology Ecology, vol. 67, no. 2, pp. 293-307, 2009. 


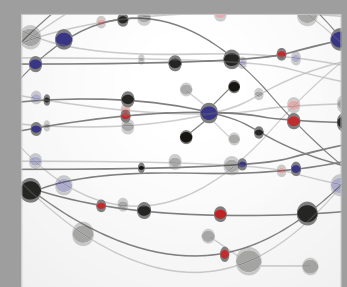

The Scientific World Journal
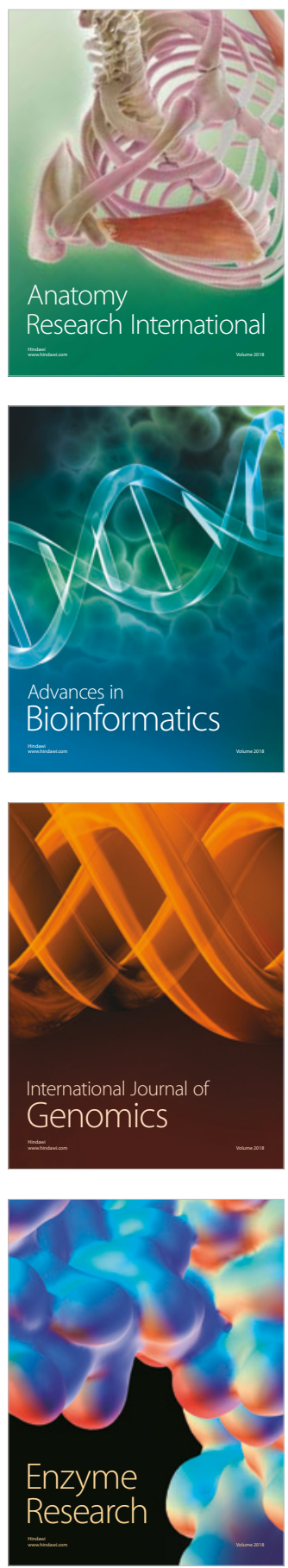
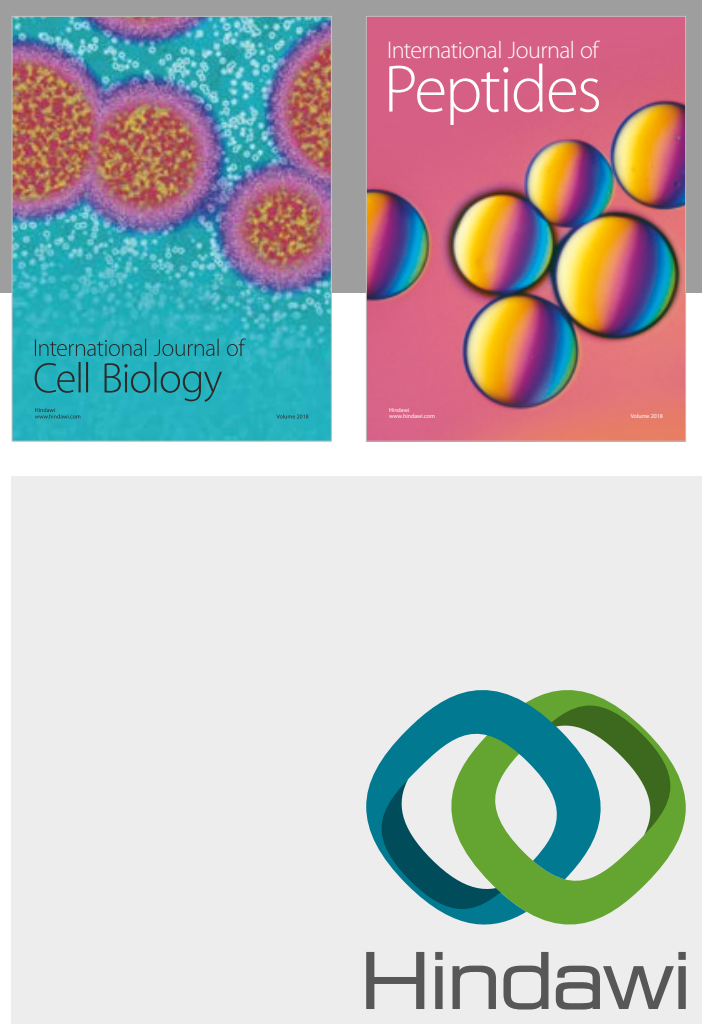

Submit your manuscripts at

www.hindawi.com
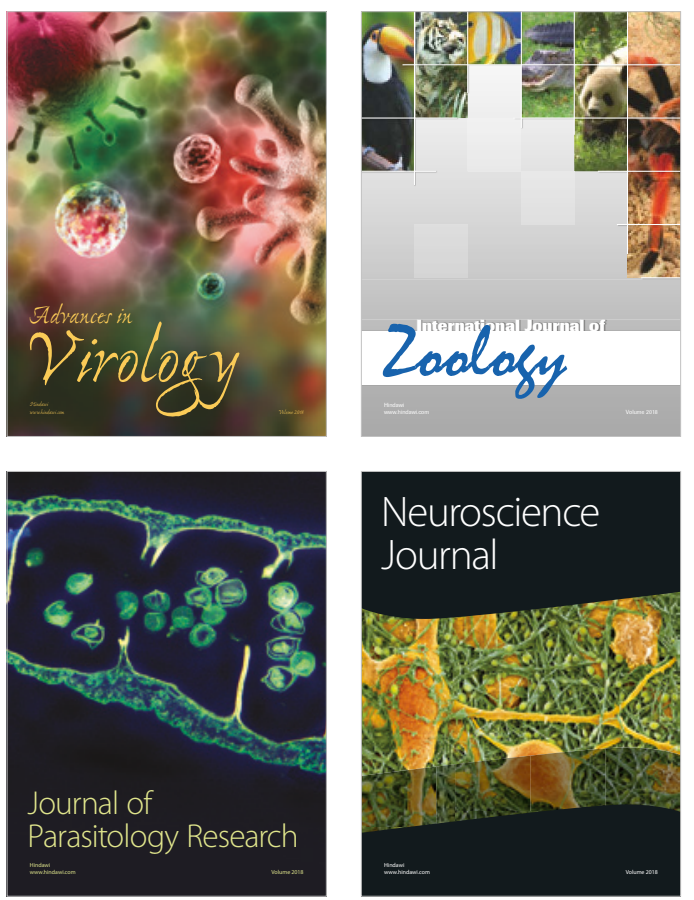
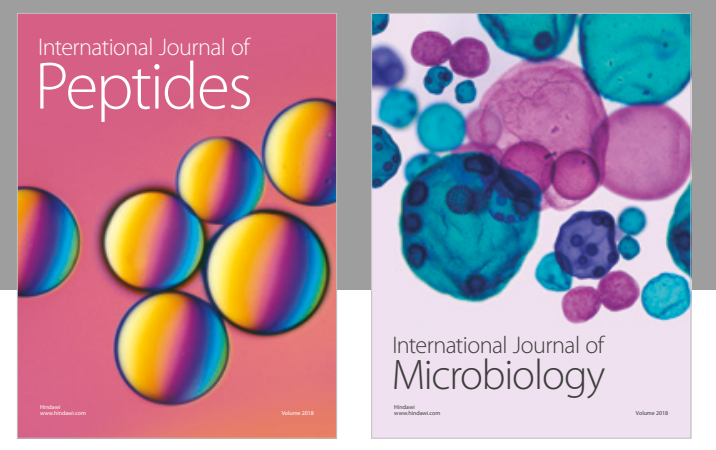

nternational Journal of Microbiology
Journal of
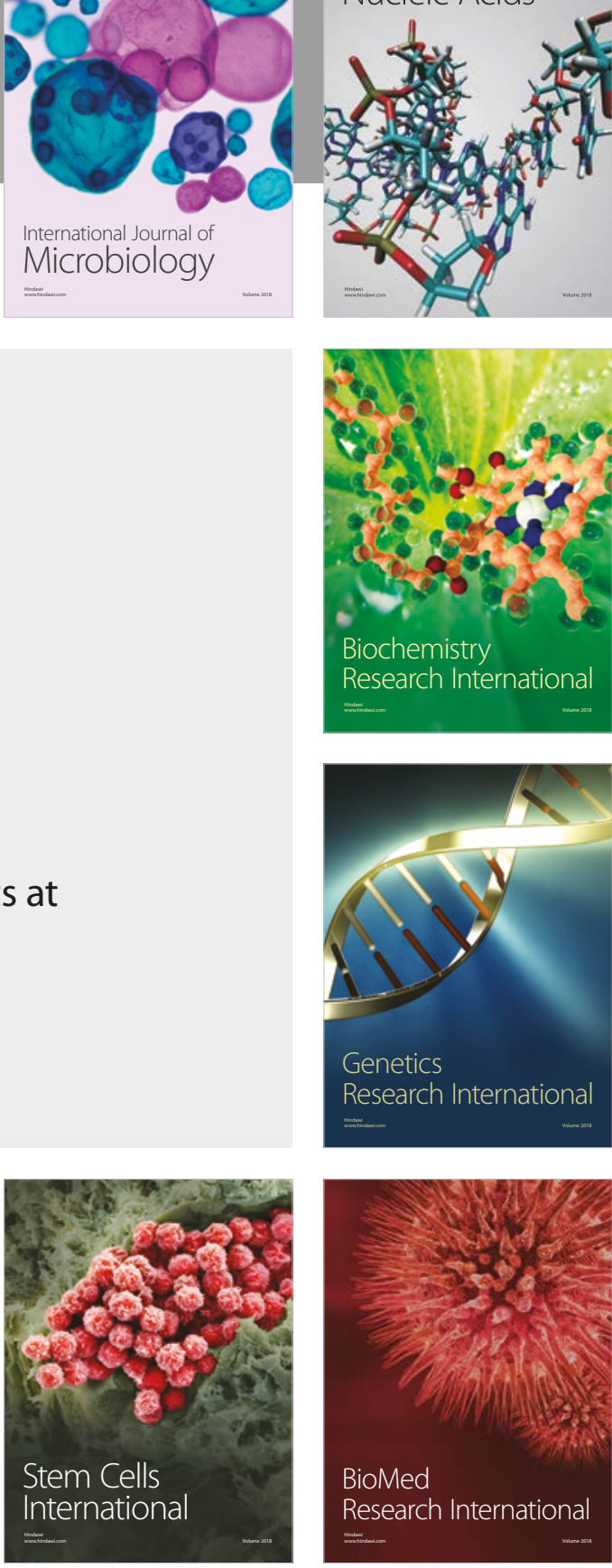
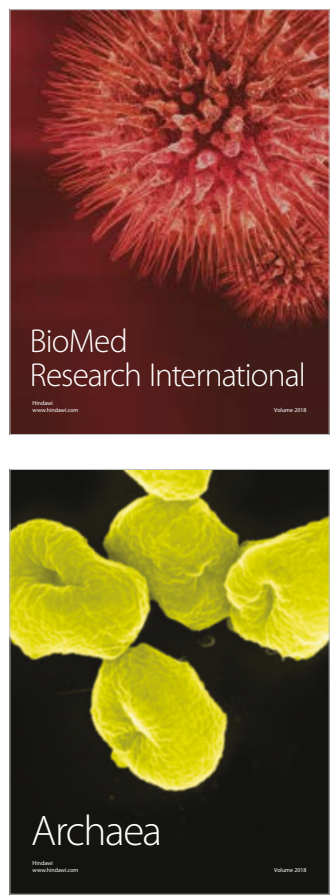